\title{
Foreign Language Moral Education under the Guidance of Cultural Security Approach
}

\author{
Yuan Jie $\mathrm{J}^{1, \mathrm{a}}$, Lan Jie $\mathrm{Ji}^{\text {, }}$ \\ ${ }^{1}$ Department of College English Education Center, Nanfang College, Guangzhou, 510970, China \\ ${ }^{2}$ Department of College English Education Center, Nanfang College, Guangzhou, 510970, China \\ ayjure2005@163.com \\ b*22395595@qq.com
}

Lan Jie is the corresponding author.

\begin{abstract}
In the process of globalization, maintaining and strengthening national cultural security is of strategic significance for ensuring national security, increasing national cohesion and protecting cultural diversity. Foreign language teaching not only provides language education for cultural exchange, but also is closely related to cultural inheritance and cultural communication. This study explores the implementation of cultural security theory in foreign language education, the current situation of cultural security education, cultural security education strategies, the moral education in foreign language curriculum, with the cultivation of intercultural communication talents to achieve the goal of maintaining national cultural security.
\end{abstract}

Keywords: Moral Education in FLT, Cultural Security, Cultivation of Intercultural Communication Competence

\section{文化安全教育视域下的外语课程思政建设}

\section{袁洁 ${ }^{1, a}$ 蓝洁 ${ }^{2,}$ b*}

广州南方学院大学英语教学中心, 广州, 中国

广州南方学院大学英语教学中心, 广州, 中国

ayjpure2005@163.com

b*22395595@qq.com

\section{蓝洁是本文通讯作者}

摘要

在全球化进程中, 维护和加强国家文化安全对于保障国家安全、增加民族凝聚力和保护文化多样性具有战略意 义。外语教学不仅为文化交流提供了语言教育, 更关系到文化传承和文化传播。本研究通过阐述外语教育中的 文化安全理论, 反思文化安全教育现状, 探寻文化安全教育策略, 探究外语课程思政模式探究, 培养跨文化交际 人才，达到维护国家文化安全的目标。

关键词: 外语课程思政，文化安全，跨文化交际人才培养 


\section{1. 前言}

2020 年 6 月, 教育部发出全面推进课程思政建 设的建议，把课程思政融入外语教学中。在全球化时 代, 政治、商业、科技和文化交流日益密切。维护和 加强国家文化安全对于保障国家安全、增加民族凝聚 力和保护文化多样性具有战略意义。外语教学作为文 化交流的前沿,一方面为文化交流提供了语言教育, 另一方面更关系到中国文化传承、文化传播和文化安 全。作为外语教育工作者, 我们需要时刻警惕文化教 育安全方面的隐患, 积极应对"西方中心主义"和”文 化帝国主义”, 克服外语教学实践和外语习得中”自我 殖民主义”, 推进外语课程思政的实施, “提高大学 生思想道德修养、人文素质、科学精神、宪法法治意 识、国家安全意识和认知能力”（教育部, 2020）。

\section{2. 外语教育的文化安全理论及相关研究}

\section{1.外语教育中的文化安全内涵}

文化是一个国家的灵魂, 文化与语言紧密相连。 我们的国家文化安全建立在具有社会主义特色的社 会制度、文化价值观和行为道德准则上。石中英教授 指出”国家内的文化安全” (cultural security in a nation/state), 即主权国家的主流文化价值体系建 立于意识形态、社会基本生活制度、语言符号系统、 知识传统、宗教信仰, 要避免主要文化要受到内部或 外部敌对力量的侵蚀、破坏和颠覆, 从而确保主权国 家享有充分完整的文化主权, 具备同国家政治、经济 发展协调一致、良性互动, 人民保持高度民族文化认 同。换言之, 文化安全是人们不用担心在全球化影响 下本国文化特征消减所产生的安全感。

语言作为文化的重要组成部分, 反映了文化的历 史、发展和特征。外语教育层面的文化安全体现在其 能够有力促进不同文化间的平等交流与互动, 实现共 同发展。强化国家文化安全意识, 在外语教学实践中, 避免学生被所学目的语文化同化, 既要学习接纳外语 国家文化, 强调语言输入, 也要注重深入了解本国文 化, 在对外交流中发扬光大民族传统和文化, 增强民 族文化的主体性, 维护中华民族文化地位。

\section{2. 各国外语教育政策与国家文化安全}

政策以解决社会问题为目的, 对社会问题的解决 起着导向作用 (Johnson, 2004)。语言政策的导向作 用体现在视语言为资源和权力, 促进语言发展。纵观 各国外语教育政策, 美国在 911 事件之后推出”国家 安全语言计划”, 改变以往排斥外语教育的态度, 在国 家利益框架中确定”关键性语言”战略, 把国民的外语 能力提升到国家竞争力、维护和加强国际优势的高度。 欧盟长期以来致力于外语教育战略规划, 2017 年前 推出《欧洲语言共同参考框架-学习、教学及评估》, 仅一年后于 2018 年推出英法扩展版, 强调语言的战
略重要性, 鼓励多语教育, 维护语言和文化的多样性, 致力于保护人类社会语言文化的生态平衡。日本强调 “实用主义”, 其外语政策演变见证了其寻找国际定位、 探索自身发展的历程。我国的外语教育政策经历了建 国初期俄语独领风骚, 改革开放后英语教育成为主流。 进入 21 世纪后我们外语教育重新定位, 反思过于强 调语言、文化输入而忽略了传统文化传承和文化输出 的问题, 将如何保证国家利益的议题引入了外语教育 研究和实践中。

\section{3. 我国外语教育的文化安全现状和挑战}

\section{1. 外语教育的价值取向}

外语教育关系到国家文化安全、文化传统传承以 及培养世界公民, 目前我国外语教育实践在维护加强 国家文化安全上存在以下严重问题。首先, 我国外语 教育的价值取向重语言工具性, 忽略人文教育理念和 价值取向。其次我国外语教育教学中使用的教材偏向 于西方文化再现, 中国本土文化较少。教材使用的文 章选自由美国、英国、澳大利亚等英语为母语的作者 编写, 介绍西方社会生活、文化传统和宗教信仰, 其 背后的价值观念深入影响到本国文化的深层领域, 多 元文化直接挑战我们的核心价值观念。教师在外语教 育中应当树立科学文化观, 使学生认识到多元文化的 平等而非优越性。

\section{2. 外语教育中的本土文化教育缺失}

作为文化认同建构活动, 外语教育有利于实现文 化共享。在外语教育中加强本土文化教育, 有助于增 强文化认同, 培养民族自豪感, 在交流的过程中达成 民族文化价值认可和共识。通过外语学习, 了解他国 对本国民族文化的认识, 通过不同的文化角度, 更进 一步认识自我。同时加强本土历史、文化的学习。最 后利用所学的外语知识把本土文化介绍、传播出去, 弘扬中华民族文化和精神。

\section{4. 外语教育的文化安全教育策略融入外语课 程思政路径研究}

\section{1. 加强宣传, 培养文化自觉与文化自信意识}

文化自觉是指生活在一定文化中的人对其文化 有自知之明, 并对其发展历程有充分的认识（费孝通 2009）。“和而不同”的文化观应当在在全球范围内提 倡, 即”各美其美, 美人之美, 美美与共”, 求同存异, 化 解矛盾。费孝通强调”自律”的原则, 外语教育一方面 要注重学生的主观能动性, 另一方面也不能忽视外语 教育的导向作用。文化自信, 是特定的文化主体对自 身的历史文化、物质创造及生活方式等精神和物质方 面的整体认同与充分肯定, 彰显着该文化主体的本质 特征和精神风貌（王旭 2019）。习近平总书记在十 九大报告中强调要 “不忘初心，牢记使命”。只有在 
原有传统文化的基础上, 吸收国外优秀的科学精神才 能实现中华民族的伟大复兴。

\section{2. 强调批判性思维, 促进文化平等}

批判性思维如果只是按照字面意思理解很容易 误导读者。批判性思维不是为了攻击、批倒对方。学 者钟启泉提出批判性思维非常重要的两点“倾听”与” 反思”, 对外语教育有着指导性作用。外语学习中强调 目的语的文化学习, 倾听目的语, 准确解释 “论据, 逻 辑与情感” 是批判性思维培养的第一步。第二, 要反 思自身，对于思考的错误和偏差采取怀疑态度。一方 面不能在没有了解目的语文化的前提下攻击他人, 另 一方面也要避免不加思考全盘接受，对自我文化贬低。

\section{3. 外语课程思政下的跨文化交际人才培养, 促进文化传承与文化创新}

跨文化教育通过教育进行文化差异比较时, 培养 批判性思维, 促进种族间差异的理解, 重视人类与生 俱来的权利, 尊重价值观差异, 理解生活方式选择的 不同, 达到全人类和谐共处。 《大学英语教学指南》 (2020) (以下简称《指南》) 对我们的大学英语教学提 出, 在培养学生的英语综合应用能力的基础上, 把大 学英语的教学内容分为“通用英语”、“专门用途英语” 和”跨文化交际”三部分, 突出强调了“跨文化交际”是 培养学生英语应用能力的重要途径和手段。根据这份 《指南》, 大学英语教学除了注重语言教学, 也应该从 跨文化交际能力培养的角度出发, 设置课程和教学内 容, 扩展学生的国际文化视野, 同时重视本族文化对 外传播, 培养学生跨文化交际意识、提高跨文化交际 能力, 加强国家文化安全意识。

跨文化外语教学根据语言输入和语用输出可分 为三个层次: 词汇、语法教学, 进行文化意义对比; 语 篇教学, 进行内容分析来定位文化价值; 跨文化语用 迁移和批判性评价。相对于跨文化外语课堂教学, 校 园活动更能体现出检验语言输出的重要地位。根据外 语习得理论和实践证明, 沉浸式的语言环境是学习语 言的最佳途径。因此学校和外语教师应该为学生创设 有趣、轻松的课内外英语学习氛围, 利用大学生年轻 旺盛精力、探求未知的好奇心和无畏精神, 共同搭建 有国际视野的跨文化交流活动。

为检验学习者的外语学习, 提高跨文化交际能力, 与外语教育相结合的校园文化活动建议采取以下三 种形式。一、重视外语基础知识积累, 通过记单词、 演讲和翻译等传统形式的语言比赛, 利用超星、慕课 等网络平台促进师生交流, 增加语言练习和使用机会。 二、走出去, 推销中国文化。从教育投入和产出来看, 走出去不是指高消费地组织学生走出国门, 尤其是在 疫情的影响下, 而要利用现代化网络传媒, 向世界发 出中国青年人的声音。如录制视频, 用英文介绍当地 文化现象, 向世界推销本族文化; 通过角色扮演来重 现案例, 对文化现象进行国别比较和分析; 采访在中
国生活、学习、工作的外国人以及在学校进行教学工 作外国教师。通过采访活动, 学生有机会直面地了解 外国人在中国的生活状况, 以主人公的身份思考人类 价值观、如何改善种族和国家关系, 同时向外国人提 出在中国生活的建议。这样的实践交流活动, 有利于 培养学生运用所学的外语和跨文化交际知识应用到 实际生活中, 为学生创设跨文化交际环境, 成功进行 跨文化交流。这些活动拍摄成视频资料保存下来, 上 传在社交网站上与对中国文化感兴趣的人分享, 尤其 是准备来中国学习、生活的外国人, 他们对学生的作 品有着刚性的需求。三、请进来, 邀请在中国学习、 生活的外国人来学校参与文化交流活动, 与相关国内 外组织形成长期合作关系。如开展讲座, 中国学生和 外国学生参与讨论, 共同完成任务, 通过各种形式充 分展示各自的文化。学生在线上交流中, 亲身体验文 化差异, 探索和发现如何运用外语进行流畅的沟通与 交流。

在跨文化交流实践活动前, 对学生进行文化安全 教育显得尤为重要。通过外语培训, 提高语言交流自 信; 学习、介绍中国优秀文化, 培养文化自觉和文化 自信; 了解目的语文化优缺点, 增强文化安全意识, 避免被“文化殖民”。

\section{5. 结论}

我国外语教育应该从文化安全角度出发, 引导学 生对本民族文化进行深刻学习, 帮助他们树立正确的 文化意识和价值观, 提升民族文化认同感，从而实现 “立德树人” 的外语课程建设目标。外语教师只有在 外语教育中坚守本民族的特色文化, 才能培养优秀跨 文化交际人才, 在国际交流过程中赢得平等地位, 切 实维护好国家文化安全。

\section{项目基金}

2019 年广东省教学改革项目《移动网络平台超 星学习通在大学英语项目式混合课堂中的行动研究》, 项目编号: GDJG1905; 2020 年全国高校外语教学科 研项目《“互联网+”时代混合式外语教学模式构建》, 项目编号：2020GD0083; 广东省高等教育学会 “十三 五” 规划 2020 年度高等教育研究专项课题《终身教 育理论对大学英语教师科研能力发展的启示》, 项目 编号：20GYB39；2021 年广东省高等教育学会 “十四 五” 规划高等教育研究课题《新文科背景下跨文化交 际能力培养模式探究》, 项目编号 21GYB166; 2021 年 广州南方学院党建课题《自媒体视域下党史教育融入 外语思政教育实践探索》, 项目编号: 2021ZS02, 阶 段性研究成果。

\section{REFERENCES}

[1] Ministry of Education of the People's Republic of China. (2020) Guiding outline of curriculum ideological and political construction in higher 
education.

http://www.moe.gov.cn/srcsite/A08/s7056/202006/t 20200603_462437.html.2020.

[2] Johnson, D. (2004) Language Policy Discourse and Bilingual Language Planning. Work-ing Papers in Educational Linguistics, 19(2):73-97.

[3] Fei, X .(2010) Culture and Cultural Consciousness. Qunyan Press, Beijing.

[4] Li, X. (2016) Research on cultural security in foreign language education. Educational Research and Experiment, 4: 82-87.

[5] Shi, Z. (2004) Study on national cultural security. Journal of Beijing Normal University (Social Sciences), 3: 5-14.

[6] Zeng, M. (2012) Response to the problem of cultural security in foreign language education, Educational Research and Experiment, 3: 60-63.

[7] Wang, X; Wang, J. (2019) The dilemma of cultural confidence and problem-solving, Legal System and Society, 12: 235-236. 